\title{
HUBUNGAN LINGKUNGAN KERJA DAN RELIGIUSITAS DENGAN PENERAPAN K3 DI RUMAH SAKIT
}

\section{Devita Sari}

STIKES Widyagama Husada

\section{Corresponding author:}

Devita Sari

STIKES Widyagama Husada

Email: devita.sariok@gmail.com

\section{Article Info:}

Dikirim: 15 Januari 2019

Ditinjau: 17 Januari 2019

Diterima: 21 Januari 2019

DOI:

https://doi.org/10.33475/jikmh.v8i2.189.

\begin{abstract}
Occupational Health and Safety Efforts must be carried out to realize optimal work productivity in all workplaces including in hospitals. One installation in the hospital that needs to get the attention of the work environment and the application of occupational safety and health is the nutritional installation, this is because based on the preliminary study data there are mild to moderate workplace accidents. The research design used in this study is quantitative analysis methods with a cross-sectional approach. A sample of 42 employees in the production section at the nutritional installation of $R S$ " $X$ " with the total sampling method. While the statistical test used is the Spearman correlation test.. The bivariate test results using spearman correlation showed that there was a relationship between the work environment and religiosity with the application of $K 3$ ( $p=0.000 ; p$ $=0.042$ ). The work environment with the implementation of $K 3$ shows a fairly strong level of relationship that is equal to 0.599 , while for religiosity with the application of K3 shows the level of weak or low relationship that is equal to 0.316. Overall employees in the production department at the " $X$ " Nutrition Hospital installation feel comfortable with the current work environment. The work environment has met the standards or regulatory quality standards. While religiosity is more to privacy which is influenced by organizational culture and work culture.
\end{abstract}

\section{Keywords : work environment; religiosity; K3 implementation}

\begin{abstract}
Abstrak
Upaya Kesehatan dan Keselamatan Kerja harus diselenggarakan untuk mewujudkan produktivitas kerja yang optimal di semua tempat kerja termasuk di dalam Rumah Sakit. Salah satu instalasi di Rumah Sakit yang perlu mendapatkan perhatian lingkungan kerja dan penerapan K3 yaitu instalasi gizi, hal ini karena berdasarkan data studi pendahuluan terdapat kejadian kecelakaan kerja ringan sampai dengan sedang. Desain penelitian yang digunakan pada penelitian ini adalah menggunakan metode analisis kuantitatif dengan pendekatan Cross-sectional. Sampel 42 orang karyawan bagian produksi di instalasi gizi RS " $X$ " dengan metode total sampling. Sedangkan uji statistik yang digunakan adalah uji korelasi spearman. Hasil uji bivariat menggunakan korelasi spearman didapatkan bahwa ada hubungan antara lingkungan kerja dan religiusitas dengan penerapan K3 $(\mathrm{p}=0.000 ; \mathrm{p}=0.042)$. Lingkungan kerja denga penerapan K3 menunjukan tingkat hubungan yang cukup kuat yaitu sebesar 0.599, sedangkan untuk religiusitas dengan penerapan K3 menunjukan tingkat hubungan yang lemah atau rendah yaitu sebesar 0.316 . Secara keseluruhan karyawan bagian produksi di instalasi Gizi RS "X" merasa nyaman dengan lingkungan kerja yang ada pada saat ini. Lingkungan kerja sudah memenuhi standard atau baku mutu peraturan. Sedangkan religiusitas lebih kepada privasi yang dipengaruhi oleh budaya organisasi dan budaya kerja.
\end{abstract}

Kata Kunci : Lingkungan Kerja; Religiusitas; Penerapan K3 


\section{PENDAHULUAN}

Upaya Kesehatan dan Keselamatan Kerja harus diselenggarakan untuk mewujudkan produktivitas kerja yang optimal di semua tempat kerja, khususnya tempat yang mempunyai risiko bahaya kesehatan, mudah terjangkit penyakit. Sejalan dengan itu, maka rumah sakit termasuk ke dalam kriteria tempat kerja dengan berbagai potensi bahaya yang dapat menimbulkan dampak kesehatan (Kepmenkes, 2010).

Untuk meningkatkan keselamatan dan kesehatan pekerja agar dapat berkualitas dan bekerja dengan baik salah satu faktor yang harus diperhatikan yaitu lingkungan tempat kerjanya. Menurut Nitisemito (1992:183), bahwa lingkungan kerja adalah segala sesuatu yang ada disekitar para pekerja dan yang dapat mempengaruhi dirinya dalam menjalankan tugas-tugas yang dibebankan. Dimana lingkungan kerja merupakan kondisi-kondisi material dan psikologis. Maka dari itu rumah sakit harus menyediakan lingkungan kerja yang memadai seperti lingkungan fisik (tata ruang yang nyaman, lingkungan yang bersih, pertukaran udara yang baik, warna, penerangan yang cukup maupun musik yang merdu), serta lingkungan non fisik (suasana kerja pekerja, kesejahteraan pekerja, hubungan antar sesama pekerja, hubungan anatar pekerja dengan pimpinan).

Lingkungan kerja yang aman dan sehat akan membawa dampak yang positif bagi orang-orang yang berada di dalamnya. Menurut Rivai (2009) lingkungan kerja yang sehat dan aman bermanfaat meningkatkan efisiensi dan kualitas pekerja yang lebih berkomitmen, menurunkan biaya-biaya kesehatan dan asuransi, kompensasi pekerja, dan pembayaran langsung yang lebih rendah karena menurunnya pengajuan klaim, fleksibilitas, serta rasio seleksi tenaga kerja yang lebih baik.

Selain memperhatikan faktor lingkungan kerja yang terdiri dari lingkungan fisik dan non fisik, faktor lain yang tak kalah pentingnya yaitu penerapan keselamatan dan kesehatan kerja di rumah sakit. Berdasarkan data Jamsostek (2012) (dalam Ilfani dan Rini, 2013), jumlah tenaga kerja pada tahun 2012 menunjukan terdapat 9.056 kasus kecelakaan kerja. Dari jumlah tersebut 2.419 kasus mengakibatkan meninggal dunia. Penerapan K3 pada setiap instansi tentunya sudah masuk dalam standar operasional, akan tetapi hal ini juga dipengaruhi oleh perilaku dan kesadaran pegawai. Salah satu unsur dalam pembentukan perilaku adalah religiusitas.

Dalam Islam perilaku seseorang seharusnya mencerminkan hubungan dirinya dengan Allah SWT. Menurut Rokeach dan Bank (Sahlan,2011) mengartikan keberagamaan atau religiusitas merupakan suatu sikap atau kesadaran yang muncul didasarkan atas keyakinan atau kepercayaan seseorang terhadap suatu agama. Sikap keagamaan merupakan suatu keadaan yang ada pada diri seseorang yang mendorongnya untuk bertingkah laku sesuai dengan kadar ketaatannya terhadap agama (Jalaluddin,2010). Dengan adanya perilaku yang didasari oleh religiusitas,maka manusia dalam melakukan aktivitasnya sesuai dengan ketentuan agama, sesuai dengan perintah Tuhannya dengan tujuan mendapatkan keridhaan-NYA.

Rumah Sakit "X" merupakan salah satu rumah sakit di kabupaten Malang yang menjalankan fungsinya di bidang medis dan secara khusus melakukan perawatan mental. Rumah sakit ini terdiri dari beberapa unit pelayanan maupun beberapa instalasi seperti instalasi rawat jalan, instalasi rawat inap, instalasi gawat darurat, instalasi laboraturium, instalasi kesehatan lingkungan, instalasi gizi, instalasi radiologi, dan lain sebagainya. Salah satu intalasi yang perlu mendapatkan perhatian lingkungan kerja dan penerapan K3 yaitu instalasi gizi, hal ini karena berdasarkan data studi pendahuluan yang telah dilakukan data laporan kecelakaan kerja yang tersedia dapat diketahui bahwa jumlah kasus kecelakaan kerja (tersiram air panas) pada tahun 2017 adalah sebanyak 10 kecelakaan. Sedangkan untuk kecelakaan lain yang pernah terjadi seperti tangan tersayat pisau, terpleset saat bekerja, tangan terkena alat-alat dapur yang panas dan lain sebagainya tidak dicatat atau tidak di data. Menurut informasi dari instalasi gizi hal ini dikarenakan 
mereka mempunyai tim pertolongan pertama kecelakaan sehingga langsung ditangani tanpa di bawa ke IGD. Sehingga kejadian kecelakaan kerja tersebut tidak di catat pada data kecelakaan kerja. Berdasarkan uraian diatas maka lingkungan kerja fisik dan non fisik serta keselamatan dan kesehatan pekerja harus diperhatikan dan diterapkan pada instalasi gizi RS "X”.

\section{METODE}

Desain penelitian yang digunakan pada penelitian ini adalah menggunakan metode analisis kuantitatif dengan pendekatan Cross-sectional yang bertujuan untuk menganalisa hubungan lingkungan kerja dan religiusitas terhadap penerapan kesehatan dan keselamatan kerja (K3) pada pekerja di instalasi gizi Rumah Sakit "X". Sampel penelitian sebanyak 42 orang dengan teknik total sampling. Uji Analisis Statistik menggunakan correlation rank spearman signifikansi $(\alpha)=0.05$

\section{HASIL DAN PEMBAHASAN}

Berdasarkan Tabel 1.Hubungan Lingkungan Kerja dengan Penerapan Keselamatan dan Kesehatan Kerja menjelaskan bahwa hasil uji statistik korelasi spearman diperoleh hasil tingkat signifikansi sebesar $0.000<\alpha$ (0.05), artinya Ho ditolak dan H1 diterima, ada hubungan secara signifikan antara variabel lingkungan kerja dengan penerapan K3. Sedangkan pada tabel 2. Hubungan Religiusitas dengan Penerapan Keselamatan dan Kesehatan Kerja, menjelaskan bahwa uji statistik korelasi spearman diperoleh hasil tingkat signifikansi sebesar $0.04<\alpha(0.05)$, artinya Ho ditolak dan H1 diterima, ada hubungan secara signifikan antara variabel religiusitas dengan penerapan $\mathrm{K} 3$

\section{PEMBAHASAN}

\section{a) Hubungan Lingkungan Kerja dan Penerapan K3 di Rumah Sakit "X"}

Berdasarkan tabel 1 diperoleh hasil bahwa ada hubungan secara nyata atau signifikan antara lingkungan kerja dan penerapan K3. Tingkat hubungan dapat dilihat pada nilai $r=0.599$, ini menunjukan hubungan yang positif diantara kedua variabel. Menurut Priyatno (2010) hal tersebut menunjukan hubungan yang cukup kuat karena memiliki rentang $0.40-0.591$. Adanya hubungan yang cukup kuat antara lingkungan kerja dan penerapan K3 menunjukan bahwa karyawan merasa nyaman dengan lingkungan kerja fisik yang ada di Rumah Sakit "X"

Hal ini sejalan dengan penelitian yang dilakukan Anggraeni dan Zulaifah (2008) yang menyebutkan ada hubungan antara persepsi iklim keselamatan dan perilaku keselamatan, dimana Arezes dan Miguel (2008), serta Larsson, Pousette, dan Torner (2008) menjelaskan bahwa lingkungan kerja fisik merupakan salah satu dimensi iklim keselamatan. Dimensi iklim keselamatan lainnya yang sering muncul dalam

Tabel 1. Hubungan Lingkungan Kerja dengan Penerapan Keselamatan dan Kesehatan Kerja (K3) Correlations

\begin{tabular}{lllrr}
\hline & & $\begin{array}{c}\text { Lingkungan } \\
\text { Kerja }\end{array}$ & $\begin{array}{c}\text { Penerapan } \\
\text { K3 }\end{array}$ \\
\hline $\begin{array}{l}\text { Spearman's } \\
\text { rho }\end{array}$ & $\begin{array}{l}\text { Lingkungan } \\
\text { Kerja }\end{array}$ & $\begin{array}{l}\text { Correlation } \\
\text { Coefficient } \\
\text { Sig. } \\
(2-\text {-tailed })\end{array}$ & 1.000 & $.599^{*}$ \\
& & &. & .000 \\
& & 4 & 42 & 42 \\
\hline
\end{tabular}

*. Correlation is significant at the 0.05 level (2-tailed). beberapa penelitian adalah pentingnya sikap kelompok kerja terhadap keselamatan (Zohar dan Luria, 2005), hal ini bisa dikatakan bahwa lingkungan kerja non fisik juga merupakan salah satu dimensi iklim keselamatan. Permen Ketenagakerjaan no. 5 tahun 2018 juga mengatur tentang lingkungan kerja baik fisik maupun psikologi.

b) Hubungan Religiusitas dengan penerapan K3 di Rumah Sakit "X" 
Tabel 2. Hubungan Religiusitas dengan Penerapan Keselamatan dan Kesehatan Kerja Correlations

\begin{tabular}{lllrr}
\hline & & $\begin{array}{c}\text { Penerapan } \\
\text { K3 }\end{array}$ & \multicolumn{2}{c}{$\begin{array}{c}\text { Religius } \\
\text { itas }\end{array}$} \\
Spearma & Penerapa & Correlation & 1.000 & $.316^{*}$ \\
n's rho & $\mathrm{n} \mathrm{K3}$ & Coefficient & & \\
& & Sig. (2-tailed) &. & .042 \\
& & $\mathrm{~N}$ & 42 & 42 \\
\hline
\end{tabular}

*. Correlation is significant at the 0.05 level (2-tailed).

Berdasarkan Tabel 2 menunjukan bahwa ada hubungan secara signifikan antara religiusitas dengan penerapan K3 Rumah Sakit "X", sedangkan tingkat hubungan sebesar r=0.316. Menurut Priyatno (2010) tingkat hubungan menunjukan bahwa hubungan antara religiusitas dan penerapan $\mathrm{K} 3$ lemah karena berada pada rentang $0.3-0.44$.

Religiusitas (keberagaman) adalah hal-hal yang berhubungan dengan aspek agama yang terkait dengan kehidupan manusia sehari-hari yang bukan hanya terjadi ketika seseorang melakukan ibadah ritual saja, melainkan juga ketika melakukan aktifitas sehari-hari. Lemahnya hubungan religiusitas dengan penerapan K3 di Rumah Sakit "X" karena beberapa faktor, salah satu faktor pendukung yaitu adanya SOP dalam melakukan pekerjaan yang terkait dengan penerapan K3. Sehingga karyawan secara otomatis akan mematuhi peraturan atau SOP yang ada. Pengalaman karyawan tersebut pada akhirnya menjadi kebiasaan, dan karyawan menjadi taat. Hal ini termasuk doktrin organisasi atau manajemen agar bisa mencapai tujuan organisasi/rumah sakit sehingga bisa mengurangi kecelakaan kerja

\section{KESIMPULAN}

Dari hasil penelitian tentang hubungan antara lingkungan kerja dan religiusitas dengan penerapan K3 dapat disimpulkan sebagai berikut :

1) Ada hubungan secara signifikan antara lingkungan kerja dengan penerapan K3 di Rumah Sakit "X" dengan tingkat hubungan sebesar 0.599 yang artinya hubungan cukup kuat.

2) Ada hubungan secara signifikan antara religiusitas dengan penerapan K3 di Rumah Sakit " $X$ " tetapi tingkat hubungan sebesar 0.316 yang artinya tingkat hubungan lemah atau rendah

Saran diberikan kepada penelitian selanjutnya agar bisa dilihat secara bersama-sama hubungan semua variable dan dapat dilihat pengaruh yang lebih besar dari masingmasing variabel. Sehingga bisa digunakan sebagai saran kepada instansi terkait

\section{DAFTAR RUJUKAN}

Attfield, Robin. (2010). Etika Lingkungan Global (judul asli: The Ethics of The Global Environmental), alih bahasa: Saut Passaribu, Kreasi Wacana, Yogyakarta.

Baharuddin, Mulyono (2008) Psikologi Agama Dalam Prespektif Islam. Malang: UIN Malang Press

Darto, Mariman, (2016). Prilaku prososial bagi revolusi mental: Seri penelitian. Malang: Penerbit Selaras Media Kreasindo

Fauzan dan Tyasari,Irma. (2015). Pengaruh Religiusitas dan Etika Kerja Islami Terhadap Motivasi Kerja. Jurnal Ekonomi Modernisasi Vol. 8. 2015

Hakim dan Wijayanto, E . (2007). Spiritual Based Management: Memimpin dan Bekerja Berbasis Spiritual. Jakarta

Rahadi,dkk. (2013). Hubungan Antara Persepsi Lingkungan Kerja Fisik Dengan Perilaku Keselamatan Karyawan. Jurnal Ecopsy Vol 1 No.1 Desember 2013

Jalaluddin. (2008). Psikologi Agama. Jakarta: PT Rajagrafindo persada

Ilfani, Grisma dan Rini Nugraheni. (2013). Analisis Pengaruh Kesehatan Dan Keselamatan Kerja terhadap Kinerja Karyawan pada PT. Sinar Galesong Pratama Makasar. Skripsi. Makasar: Universitas Hasanuddin.

Kemenkes. (2010) Keputusan Menteri Kesehatan Republik Indonesia Nomor

1087/MENKES/SK/VIII/2010 tentang Standar Kesehatan dan Keselamatan Kerja di Rumah Sakit. Jakarta: Kementrian Kesehatan Republik Indonesia. 
Mangkuprawira, Sjafri. (2011). Manajemen Sumber Daya Manusia Strategik. Edisi Kedua. Bogor : Ghalia Indonesia

Messara,Leila Canan. (2014). Religious Diversity at Work: The Perceptual Effects of Religious Discrimination on Employee Engagement and Commitment. Contemporary Management Research Pages 59-80, Vol. 10, No. 1, March 2014 doi: $10.7903 / \mathrm{cmr} .12018$

Mulyadi \& Rivai. (2009). Manajemen Sumber Daya Manusia. Jakarta. Cetakan kesembilan

Priyatno,Duwi. (2010). Teknik Mudah dan Cepat Melakukan Analisis Data Penelitian Dengan SPSS, Yogyakarta, Gava Media

Sahlan, Asmaun, (2011). Religiusitas Perguruan Tinggi: Potret Pengembangan Tradisi Keagamaan di Perguruan Tinggi Islam Malang. UIN Maliki Press. Malang
Sedarmayanti, (2009). Sumber Daya Manusia dan Produktivitas Kerja. Bandung: CV Mandar Maju

Siregar, C. J. P., Amalia, L. (2004). Farmasi Rumah Sakit : Teori dan Penerapan. Edisi Pertama. Penerbit Buku Kedokteran ECG: Jakarta.

Sugiyono. (2011). Metode Penelitian Kuantitatif, Kualitatif, dan R\&D. Bandung: AFABETA, CV.

Susanti,Rita. (2015). Hubungan Religiusitas dan Kualitas Kehidupan Kerja dengan Organizational Citizenship Behavior (OCB) Pada Karyawan. Jurnal Psikologi, Volume 11 Nomor 2, Desember 2015

Rivai, Viethzal. (2008). Performance Apprasial: Sistem Yang Tepat Untuk Menulai Kinerja Karyawan dan Meningkatkan Daya Saing Perusahaan. Jakarta: TP. Raja Grafindo Persada

Cite this article as: Sari, D. (2019). Hubungan Lingkungan Kerja dan Religiusitas dengan Penerapan K3 di Rumah Sakit. Jurnal Ilmiah Media Husada. Vol. 8 No.2, halaman awal-halaman akhir. https://doi.org/10.33475/jikmh.v8i2.189. 